\section{(A) Check for updates}

Cite this: Dalton Trans., 2020, 49, 11142

\title{
Isomers in chlorido and alkoxido-substituted oxidorhenium(v) complexes: effects on catalytic epoxidation activity $\dagger$
}

\author{
Jörg A. Schachner, (D) * Ferdinand Belaj (D) and Nadia C. Mösch-Zanetti (D) *
}

\begin{abstract}
The syntheses and characterizations of oxidorhenium(v) complexes trans-dichlorido $\left[\operatorname{ReOCl}\left(\mathrm{PPh}_{3}\right)\left(\mathbf{L} \mathbf{L}_{\mathbf{a}}\right)\right]$ (trans-2a), cis-dichlorido $\left[\operatorname{ReOCl}_{2}\left(\mathrm{PPh}_{3}\right)(\mathbf{L} \mathbf{b} \mathbf{b})\right]$ (cis-2b) and ethoxido-complex [ReO(OEt)(L1b) $)_{2}$ (4b), ligated with the dimethyloxazoline-phenol ligands HL1a and HL1b are described. The bidentate ligand HL1a (2-(4,4-dimethyl-4,5-dihydro-1,3-oxazol-2-yl)-phenol) is unsubstituted on the phenol ring; ligand HL1b (2-(4,4-dimethyl-4,5-dihydro-1,3-oxazol-2-yl)-4-nitrophenol) contains a nitro group in para-position to the hydroxy group. In the reaction of precursor complex $\left[\mathrm{ReOCl}_{3}\left(\mathrm{PPh}_{3}\right)_{2}\right]$ and $\mathrm{HL1}$ a the two stereoisomers cis/trans-2a, with respect to chlorido ligands, are formed. The solid state structures of both isomers cis- and trans-2a were determined by single crystal $\mathrm{X}$-ray diffraction analysis. In contrast, with ligand HL1b, only the cis-isomer cis-2 $\mathbf{b}$ was obtained. Ethoxido-complex $\mathbf{4} \mathbf{b}$ is exclusively obtained when precursor $\left[\mathrm{ReOCl}_{3}\left(\mathrm{OPPh}_{3}\right)\left(\mathrm{SMe}_{2}\right)\right]$ is reacted with 2 equiv. of $\mathrm{HL1b}$ in ethanol in the presence of the base 2,6-dimethylpyridine (lutidine). If no lutidine is added, chlorido-complex $\left.[\operatorname{ReOCl(} \mathbf{L} \mathbf{1 b})_{2}\right](\mathbf{3 b})$ is obtained. Complexes [ReOCl$\left.\left(\mathrm{PPh}_{3}\right)(\mathbf{L} \mathbf{1 a})\right]$ (cis/trans-2a), [ReOCl$\left.\left(\mathrm{PPh}_{3}\right)(\mathbf{L} \mathbf{1 b})\right]$ (cis-2b), [ReO(OMe)(L1a) $\left.)_{2}\right]$ (4a) and $\left[\mathrm{ReO}(\mathrm{OEt})(\mathbf{L 1} \mathbf{b})_{2}\right](\mathbf{4} \mathbf{b})$ were tested as homogeneous catalysts in the benchmark reaction of cyclooctene epoxidation. The influence of isomerism and effects of ligand substitutions on catalytic activity was investigated. Based on the time-conversion plots it can be concluded that cis/trans-isomerism does not influence catalytic activity, but electron-withdrawing substituents, as in cis-2 $\mathbf{b}$, $\mathbf{3} \mathbf{b}$ and $\mathbf{4} \mathbf{b}$, show a beneficial effect.
\end{abstract}

\begin{abstract}
Received 3rd July 2020, Accepted 28th July 2020 DOI: 10.1039/d0dt02352c rsc.li/dalton
\end{abstract}

\section{Introduction}

With Herrmann's seminal papers on the convenient synthesis ${ }^{1}$ and the superior catalytic activity of methyltrioxorhenium (MTO) in olefin epoxidation and oxidation, ${ }^{2}$ a surge of research in high-valent oxidorhenium chemistry was initiated. ${ }^{3}$ In olefin epoxidation catalysis, MTO remains the most investigated and active rhenium-based catalyst to this day, reaching turnover numbers (TONs) of $>20000 .{ }^{4-6}$ However, MTO requires $\mathrm{H}_{2} \mathrm{O}_{2}$ as oxidant, which leads to formation of stoichiometric amounts of $\mathrm{H}_{2} \mathrm{O}$ in epoxidation reactions. This limits the use of MTO for epoxides which are prone to hydrolytic ring

Institute of Chemistry, Inorganic Chemistry, University of Graz, Schubertstr. 1, 8010 Graz, Austria.E-mail: joerg.schachner@uni-graz.at

$\dagger$ Electronic supplementary information (ESI) available: NMR spectra for trans$\mathbf{2 a}$, cis-2 $\mathbf{b}$ and $\mathbf{4 b}$, zoom in of ${ }^{1} \mathrm{H}$ NMR spectrum of complex $\mathbf{4} \mathbf{b}$ of the ethoxido region (Fig. S1-9); data on cyclovoltammetry; crystallographic details on data acquisition, bond lengths and angles and CCDC numbers for trans-2a (1854788), cis-2a (1854789) and cis-2b (2011198). For ESI and crystallographic data in CIF or other electronic format see DOI: $10.1039 /$ dodt02352c opening under acidic or aqueous reaction conditions. ${ }^{7}$ Complexes containing the oxidorhenium(v) $[\mathrm{ReO}]^{3+}$ core were identified as a possible solution to the ring-opening problems of MTO, as such complexes are stable in water, ${ }^{8}$ whereas MTO acts as an acid in the presence of water. ${ }^{9}$ The first two examples of such oxidorhenium(v) complexes were disclosed in 1996 and 1997, again by the group of Herrmann, employing tetra- and bidentate Schiff-base ligands. ${ }^{10,11}$ Over the next two decades several research groups around the world, including ours, contributed to oxidorhenium(v) chemistry and its application in homogeneous catalytic epoxidation of cyclooctene. ${ }^{4,8,12-15}$ We have been exploring the chemistry of oxidorhenium(v) complexes with different ON-bidentate ligands of the type $\left[\mathrm{ReOCl}_{2}\left(\mathrm{PPh}_{3}\right)(\mathrm{ON})\right]$ (referred to as monoligated) and $\left[\mathrm{ReOCl}(\mathrm{ON})_{2}\right]$ (referred to as bis-ligated) complexes.

The rich coordination chemistry and structural features of oxidorhenium(v) complexes have been extensively reviewed by Sergienko and Machura over the last few years. ${ }^{8,16,17}$ In principle there are seven stereoisomers possible for mono-ligated complexes of type $\left[\mathrm{ReOX}_{2} \mathrm{~L}(\mathrm{ON})\right](\mathrm{a}-\mathrm{g}$, Fig. 1) and six for bis- 

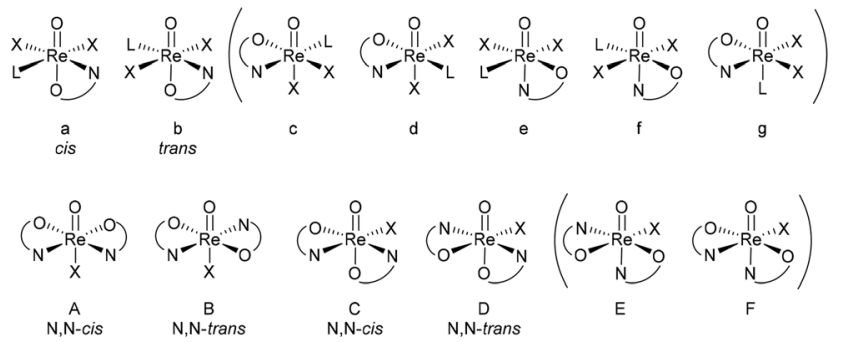

Fig. 1 Top row: possible stereoisomers $\mathrm{a}-\mathrm{g}$ for mono-ligated complexes; bottom row: possible stereoisomers A-F for bis-ligated complexes; isomers in brackets have not been isolated yet.

ligated complexes of type $\left[\operatorname{ReOX}(\mathrm{ON})_{2}\right]\left(\mathrm{A}-\mathrm{F}\right.$, Fig. 1). ${ }^{18}$ Except for isomers $\mathrm{b}, \mathrm{f}$ and $\mathrm{A}$, these complexes also show octahedral chirality.

For isomers a and $\mathrm{b}$, the cis/trans label refers to the orientation of the two X ligands. For bis-ligated isomers A-D, the $\mathrm{N}, \mathrm{N}$-cis/trans label was established in literature, referring to the position of the nitrogen atoms. Isomers $\mathrm{c}-\mathrm{g}$ and $\mathrm{E}-\mathrm{F}$ have not been observed yet. In our research, focus was placed on two classes of ON-bidentate ligands, namely pyrazole-phenol (HpyzR) as well as oxazoline (Hoz) and dimethyloxazolinephenol ligands (HdmozR), with different electron-withdrawing and -donating substituents R on the phenol moiety (Fig. 2).

The Hoz ligand led to the rare case where both $N, N$-trans and $N, N$-cis isomers of the complex $\left[\operatorname{ReOCl}(\mathrm{Oz})_{2}\right]$ were formed in equal amounts and were successfully isolated. ${ }^{19,20}$ In contrast, complexes containing a ligand from the dimethyloxazoline HL1 family have exclusively yielded $N, N$-trans complexes so far. ${ }^{19-21,22}$ Their application in two benchmark homogeneous catalytic reactions, namely cyclooctene epoxidation and perchlorate reduction was studied in a systematic manner. ${ }^{12,13,19,21,23-25}$ Whereas both mono- and bis-ligated complexes show activity in epoxidation catalysis, only the bisligated complexes are active in perchlorate reduction. In addition we found that $N, N$-trans $\left[\operatorname{ReOCl}(\mathrm{Oz})_{2}\right]$ shows superior activity in perchlorate reduction over $N, N$-cis $\left[\operatorname{ReOCl}(\mathrm{Oz})_{2}\right] \cdot{ }^{19}$ Therefore, we were interested to also test both $N, N$-cis/trans $\left[\mathrm{ReOCl}(\mathrm{Oz})_{2}\right]$ isomers in epoxidation catalysis, but in contrast to perchlorate reduction it was found that both stereoisomers displayed the same, mediocre activity in cyclooctene epoxidation (TON $=30$ and 40, resp.). ${ }^{21}$ With an electron-withdrawing $\mathrm{NO}_{2}$ substituent on the ligand, $\mathrm{N}, \mathrm{N}$-trans complex [ReOCl $\left.(\mathbf{L 1 b})_{2}\right]$ (3b) displayed much higher epoxidation activity, giving

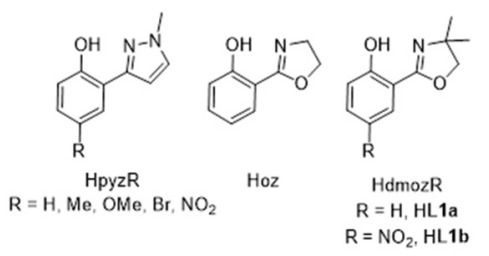

Fig. 2 Pyrazole- and oxazoline-phenol based ON-bidentate ligands investigated in oxidorhenium(v) chemistry. more than twice as many turnovers as unsubstituted complex $\left[\operatorname{ReOCl}(\mathbf{L 1 a})_{2}\right](3 \mathbf{a})(3 \mathbf{a}, \mathrm{TON}=37 ; \mathbf{3 b}, \mathrm{TON}=80) \cdot{ }^{21} \mathrm{~A}$ similar observation was made for nitro-substituted complex [ReOCl $\left.\left(\mathrm{pyzNO}_{2}\right)_{2}\right] .^{25}$ Thus, complexes equipped with electron-withdrawing substituents are one key feature for active epoxidation catalysts.

Within this manuscript we present further studies on the influence of stereoisomers and substituent effects with regards to catalytic epoxidation activity. We were able to isolate and fully characterize the two oxidorhenium(v) coordination isomers cis- and trans-2a $\left[\mathrm{ReOCl}_{2}\left(\mathrm{PPh}_{3}\right)(\mathbf{L 1 a})\right]$. The observation of two isomers is in contrast to cis-2b $\left[\mathrm{ReOCl}_{2}\left(\mathrm{PPh}_{3}\right)(\mathbf{L} \mathbf{1} \mathbf{b})\right]$, where only the cis-isomer was obtained. The stereochemistry of all three complexes was confirmed by single crystal X-ray diffraction. Bis-ligated complexes $\left[\operatorname{ReOCl}(\mathbf{L 1 a})_{2}\right] \quad(3 \mathbf{3 a})$ and $\left[\operatorname{ReOCl}(\mathbf{L 1 b})_{2}\right](3 \mathbf{b})$ react in an alcoholic solvent in the presence of a suitable base to the alcoholato complexes [ReO(OMe) $\left.(\mathbf{L 1 a})_{2}\right]_{(\mathbf{4 a})^{19}}$ and $\left[\mathrm{ReO}(\mathrm{OEt})(\mathbf{L 1 b})_{2}\right] \quad(\mathbf{4 b})$ respectively (Scheme 3). The series of complexes were used as catalysts in the epoxidation of cyclooctene allowing the investigation of the influence of stereoisomeric as well as electrophilic properties, and were compared to previously published complexes 3a, 3b and $4 \mathbf{4 a}^{19,21}$ To the best of our knowledge, complexes cis/trans-2a is the first pair such stereoisomers that is investigated in epoxidation catalysis.

\section{Results and discussion}

\section{Synthetic procedures}

A general overview of the synthesis of mono- and bis-ligated complexes with ligands HL1 is shown in Scheme 1. Precursor $\left[\mathrm{ReOCl}_{3}\left(\mathrm{PPh}_{3}\right)_{2}\right]$ exclusively yields mono-ligated complexes of type $\left[\mathrm{ReOCl}_{2}\left(\mathrm{PPh}_{3}\right)(\mathbf{L 1})\right]$, precursor $\left[\mathrm{ReOCl}_{3}\left(\mathrm{OPPh}_{3}\right)\left(\mathrm{SMe}_{2}\right)\right]$ exclusively bis-ligated complexes of type $\left[\operatorname{ReOCl}(\mathbf{L 1})_{2}\right]$, independent of the chosen metal to ligand stoichiometry.

The synthesis of mono-ligated complex $\left[\operatorname{ReOCl}_{2}\left(\mathrm{PPh}_{3}\right)(\mathbf{L 1 a})\right]$ (cis-2a) was reported in $2014 .^{19}$ During a later synthesis, after isolation of product cis-2a as previously described, ${ }^{19}$ upon further cooling of the remaining supernatant to $8{ }^{\circ} \mathrm{C}$, a small amount of a green crystalline material was obtained, giving a different ${ }^{1} \mathrm{H}$ NMR spectrum than cis-2a. This material proved

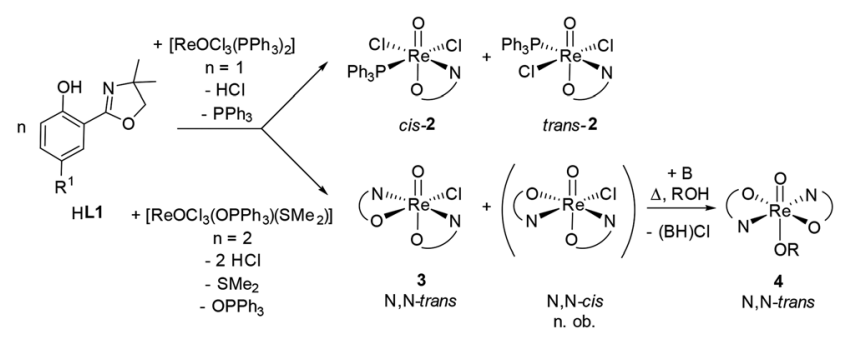

Scheme 1 General scheme of formation of complexes and their isomers with ligand HL1; abbreviations used to indicate stereoisomers are given (n.ob. = not observed; $\mathrm{B}=$ Brønsted base, e.g. 2,6-dimethylpyridine, $\mathrm{NaH}$ ). 


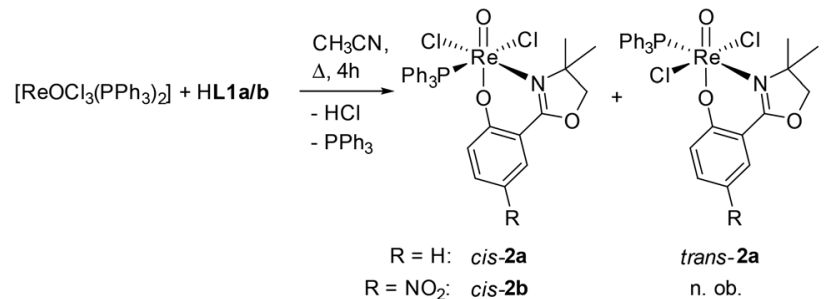

Scheme 2 Syntheses of complex cis-2a, ${ }^{19}$ trans $-2 a$ and cis-2b (n. ob. = not observed).

to be the stereoisomer trans-2a (Scheme 2). In contrast, with nitro-substituted ligand HL1b, under otherwise identical conditions, only stereoisomer cis-2b could be isolated.

The ${ }^{1} \mathrm{H}$ NMR spectrum of trans-2a shows a time-averaged $C_{\mathrm{s}}$-symmetric molecule in solution, with both methyl groups and the methylene protons of the oxazoline moiety appearing as singlets (Fig. $\mathrm{S} 1 \dagger$ ). The coordinated $\mathrm{PPh}_{3}$ ligand appears as two well-separated multiplets centered at 7.88 and $7.50 \mathrm{ppm}$ $\left(\mathrm{CDCl}_{3}\right.$, Fig. $\left.\mathrm{S} 1 \dagger\right)$. In the ${ }^{31} \mathrm{P}$ NMR spectrum, a shift of $-5.35 \mathrm{ppm}$ is observed (Fig. S3†), which is almost identical to the shift of free $\mathrm{PPh}_{3}(-5.47 \mathrm{ppm})$. Single crystals suitable for X-ray diffraction analysis of cis- and trans-2a were obtained confirming their isomeric structures (see below). trans-2a shows a limited stability in $\mathrm{CDCl}_{3}$ solution under ambient atmosphere. After several days, signals for $\mathrm{OPPh}_{3}$ are appearing.

The ${ }^{1} \mathrm{H}$ NMR spectrum of complex cis-2b gave the expected pattern of a coordinated L1b ligand moiety and a molecule of $\mathrm{PPh}_{3}$ (Fig. S4 and $\mathrm{S} 5 \dagger$ ). The coordinated $\mathrm{PPh}_{3}$ ligand shows a peak at $-17.35 \mathrm{ppm}\left(\mathrm{CDCl}_{3}\right)$ in the ${ }^{31} \mathrm{P}$ NMR spectrum (Fig. S6 $\dagger$ ). Complex cis-2b also shows a limited stability in $\mathrm{CDCl}_{3}$ solution. After several days decomposition occurs, indicated by a color change from initial green to brown, and the appearance of several new signals in the NMR spectra, which could not be assigned to a new complex.

The synthesis of chlorido-complex N,N-trans $\left[\operatorname{ReOCl}(\mathbf{L} 1 \mathbf{b})_{2}\right]$ (3b) in acetonitrile solution has been previously published (Scheme 3). ${ }^{21}$ However, when EtOH was the reaction solvent and lutidine was added, the reaction solution turned darkbrown under reflux conditions. Upon cooling of the reaction mixture, a brown micro-crystalline material could be isolated

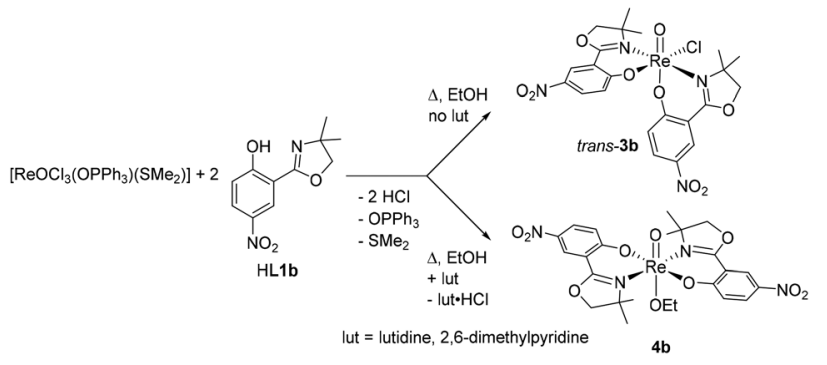

Scheme 3 Formation of $3 b$ in absence of lutidine; formation of $4 b$ in presence of lutidine in $\mathrm{EtOH}$. in high yields. In the supernatant, the by-product lutidine hydrochloride could be identified. As single crystals of high enough quality of this material could not be grown, the assignment of the structure of $\mathbf{4} \mathbf{b}$ as a symmetric ethoxido-complex (Scheme 3) is based on the following analytical data: in the ${ }^{1} \mathrm{H}$ NMR spectrum, a diagnostic quartet of doublets at $3.50 \mathrm{ppm}$ $(2 \mathrm{H})$ and a corresponding triplet at $0.81 \mathrm{ppm}(3 \mathrm{H})$ could be observed (Fig. S8 $\dagger$ ), indicating the presence of an ethoxido ligand. Furthermore, only one set of L1b ligand signals was observed, consistent with the formation of a symmetric complex (B, Fig. 1). By integration, the ratio of the ethoxido to L1b ligand moieties is $1: 2$, confirming the stoichiometry as $\left[\mathrm{ReO}(\mathrm{OEt})(\mathbf{L 1} \mathbf{b})_{2}\right]$ (Fig. S7 $\dagger$ ). The proposed structure of $\mathbf{4 b}$ (Scheme 3) is of $C_{2}$-symmetry, consistent with the observed ${ }^{1} \mathrm{H}$ NMR spectrum (3b has $C_{1}$-symmetry ${ }^{21}$ ). In the IR spectrum, the $\mathrm{Re}=\mathrm{O}$ stretching frequency is found at $912 \mathrm{~cm}^{-1}$, whereas the related band of the cis-[ReOCl $]^{3+}$ core of $3 \mathbf{b}$ is located at $962 \mathrm{~cm}^{-1}$. $^{21}$ Such a significant bathocromic shift would be expected for a trans-[ReO(OR)$]^{3+}$ core, due to competition of the ethoxido ligand for $\pi$ bonding with the metal $\mathrm{d} \pi$ orbitals. ${ }^{12,13,26} \mathrm{~A}$ mass spectrum of $\mathbf{4} \mathbf{b}$ showed a molecular ion peak with a correct isotope pattern matching for [ReO(OEt) $(\mathbf{L 1 b})_{2}$ ]. The same spectroscopic and structural features were also observed for previously published methoxido-coordinated complex $\left[\mathrm{ReO}(\mathrm{OMe})(\mathbf{L 1 a})_{2}\right](\mathbf{4 a})$, whose solid state structure was confirmed by X-ray crystallography. ${ }^{19}$ Complex 4 a was obtained in a similar fashion from a reaction in $\mathrm{MeOH}$ with residual amounts of the base $\mathrm{NaH}$ still present. In case of $\mathbf{4} \mathbf{b}$, the added lutidine played a similar role, probably by deprotonating EtOH and inducing chlorido abstraction. In absence of lutidine, expected chlorido-complex $\mathbf{3 b}$ is obtained from synthesis in EtOH (Scheme 3).

\section{Crystallography}

Single crystal X-ray diffraction analyses confirmed the stereochemistry of cis-2a, trans-2a and cis-2b. Molecular views of cis/ trans-2a are given in Fig. 3, of cis-2b in Fig. 4. Selected bond

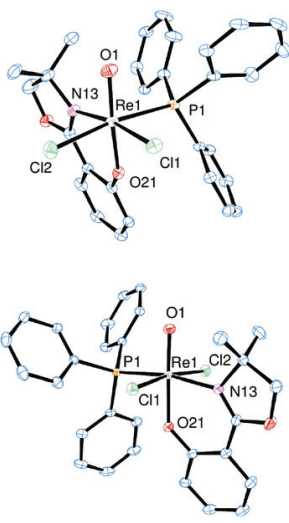

Fig. 3 Molecular views (50\% level) of complexes cis-[ReOCl$\left(\mathrm{PPh}_{3}\right)$ (L1a)] (cis-2a, top) and trans-[ReOCl$\left.\left(\mathrm{PPh}_{3}\right)(\mathrm{L1a})\right]$ (trans-2a, bottom) $(\mathrm{H}$ atoms and solvent molecules omitted for clarity). 


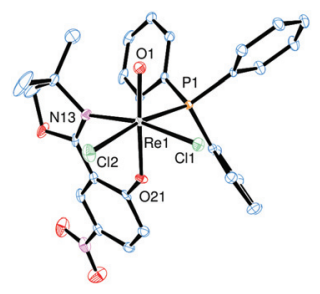

Fig. 4 Molecular view (50\% level) of complex cis-[ReOCl$\left.\left(\mathrm{PPh}_{3}\right)(\mathrm{L} 1 \mathrm{~b})\right]$ (cis-2b) (H atoms omitted for clarity).

lengths and angles are shown in Table 1. Details on crystallographic refinements can be found in the ESI. $\dagger$

Single crystals for cis-2a were obtained by slow evaporation of a saturated dichloromethane solution, for trans-2a of a saturated acetonitrile solution. Both complexes show a distorted octahedral coordination of the rhenium center, with the trans arrangement of the phenolate oxygen $\mathrm{O} 21$ to the oxido ligand O1 (Fig. 3). For trans-2a, the two chlorido ligands are in trans orientation to each other, in contrast to most previously described mono-ligated oxidorhenium(v) complexes of that type. ${ }^{12,17,19,25,27}$ Only few examples were disclosed, where both the cis and trans isomers of the same ligand set were isolated and characterized. ${ }^{28}$ For cis-2a and trans-2a, the respective $\mathrm{Re} 1=\mathrm{O} 1$ and Re1-O21 bond distances are the same within experimental error. Single crystals of cis-2b were obtained by slow evaporation of a concentrated solution in EtOAc. Complex cis-2b shows the same isomeric arrangement as cis-2a (isomer a, Fig. 1). The electron-withdrawing influence of the L1b ligand moiety is reflected by the slightly shortened Re1=O1 and elongated Re1-O21 bond, in comparison to cis-2a.

\section{Epoxidation}

The catalytic epoxidation of cyclooctene (Scheme 4) of complexes trans-2a, cis-2b and $\mathbf{4 b}$ together with the two previously published complexes cis-2a and $\mathbf{4 a}$ was investigated. The results of the two alkoxido-complexes $\mathbf{4 a}$ and $\mathbf{4} \mathbf{b}$ are compared to previously obtained epoxidation data of the respective chlorido-complexes $\mathbf{3 a}$ and $\mathbf{3} \mathbf{b} .{ }^{21}$ of particular interest was the influence on catalytic activity of the cis/trans-isomerism of $2 \mathbf{a}$ and the effect chlorido/alkoxido substitution in complexes $\mathbf{3 a} / \mathbf{4 a}$ and $\mathbf{3 b} / \mathbf{4} \mathbf{b}$. Finally, the influence of electron-withdrawing substituents was studied by comparison of catalytic activity

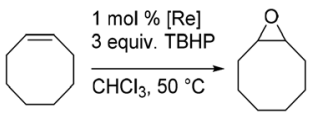

Scheme 4 Catalytic epoxidation of cyclooctene using tert-butylhydroperoxide (TBHP).

between cis-2a and cis-2b. Accordingly, all complexes were tested using 3 equiv. of tert-butylhydroperoxide (TBHP) as oxidant (Scheme 4) with a $1 \mathrm{~mol} \%$ catalyst loading in $\mathrm{CHCl}_{3}$ at $50{ }^{\circ} \mathrm{C}$. Reaction progress was monitored by withdrawing aliquots and analysis with gas chromatography mass spectrometry.

Time-conversion plots for cis/trans-2a and cis-2b are given in Fig. 5, for complexes $3 \mathbf{a} / \mathbf{b}$ and $\mathbf{4 a} / \mathbf{b}$ in Fig. 6. A summary of turnover numbers (TONs) and turnover frequencies (TOFs) can be found in Table 2. In general all tested complexes are catalytically active without induction period. The highest activities were displayed by complexes equipped with the electron-withdrawing ligand HL1b. Mono-ligated complex $\left[\mathrm{ReOCl}_{2}\left(\mathrm{PPh}_{3}\right)\right.$ (L1b)] (cis-2b) showed the highest TON of 95 after only $12 \mathrm{~h}$ of reaction time. Similarly, complex $\left[\operatorname{ReOCl}(\mathbf{L} 1 \mathbf{b})_{2}\right](3 \mathbf{b})$ reached a TON of 82, complex $\left[\mathrm{ReO}(\mathrm{OEt})(\mathbf{L} 1 \mathbf{b})_{2}\right](\mathbf{4 b})$ the essentially same TON of 84. Complexes equipped with ligand HL1a showed in general lower activities. Mono-ligated complexes $\left[\mathrm{ReOCl}_{2}\left(\mathrm{PPh}_{3}\right)\right.$

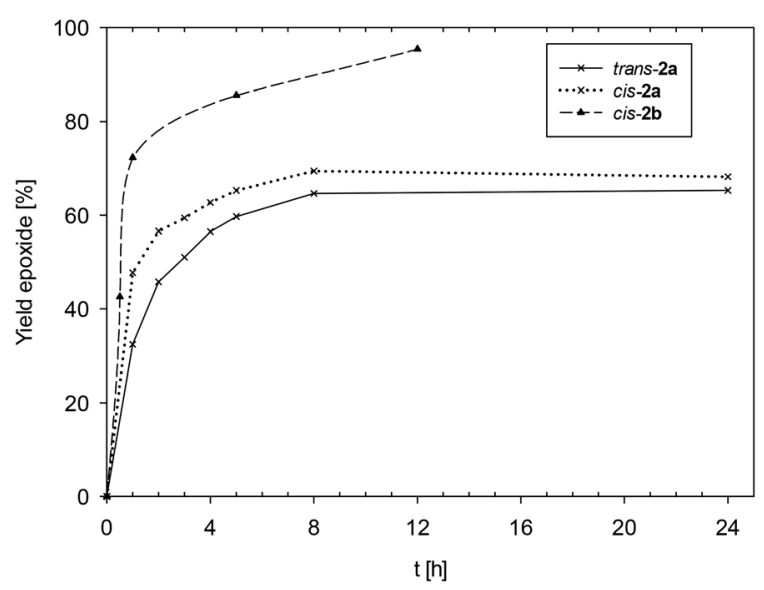

Fig. 5 Comparison of epoxide yields for isomeric complexes cis/trans$2 \mathrm{a}$ and cis-2b.

Table 1 Comparison of bond lengths $[\AA \AA]$ of cis-2a and trans-2a

\begin{tabular}{|c|c|c|c|c|c|c|}
\hline$[\AA]$ & $\mathrm{Re} 1=\mathrm{O} 1$ & $\mathrm{Re} 1-\mathrm{O} 21$ & Re1-P1 & Re1-Cl1 & $\mathrm{Re} 1-\mathrm{Cl} 2$ & Re1-N13 \\
\hline cis-2a & $1.684(3)$ & $1.947(3)$ & $2.4961(11)$ & $2.3747(11)$ & $2.4019(12)$ & $2.166(3)$ \\
\hline trans-2a & $1.6917(13)$ & $1.9481(13)$ & $2.4723(5)$ & $2.3981(4)$ & $2.4026(5)$ & $2.1423(16)$ \\
\hline cis-2b & $1.6775(19)$ & $1.9969(18)$ & $2.4749(7)$ & $2.3632(7)$ & $2.3766(7)$ & $2.155(2)$ \\
\hline$\left[{ }^{\circ}\right]$ & & O1-Re1-O21 & & $\mathrm{Cl} 1-\mathrm{Re} 1-\mathrm{Cl} 2$ & & N13-Re1-P1 \\
\hline cis-2a & & $168.16(13)$ & & $86.39(4)$ & & $94.54(10)$ \\
\hline trans-2a & & $177.71(6)$ & & $171.181(16)$ & & $168.60(4)$ \\
\hline cis-2b & & $167.51(8)$ & & $86.27(3)$ & & 168.96(6) \\
\hline
\end{tabular}




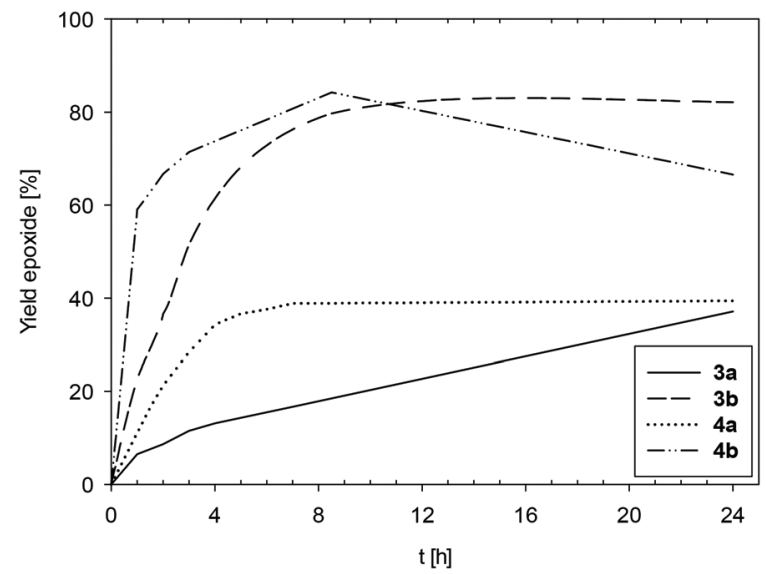

Fig. 6 Comparison of epoxide yields of complexes $3 a / 4 a$ and $3 b / 4 b$; data for $3 a-b$ was previously published. ${ }^{21}$

(L1a)] (cis/trans-2a) showed average activities (TON $=69$ and 65, resp.). The lowest overall activities were displayed by chloridocomplex $\left[\operatorname{ReOCl}(\mathbf{L 1 a})_{2}\right](3 \mathbf{a}, \mathrm{TON}=37)^{21}$ and methoxidocomplex $\left[\mathrm{ReO}(\mathrm{OMe})(\mathbf{L 1 a})_{2}\right](\mathbf{4 a}, \mathrm{TON}=39)$.

Data presented in Fig. 5 displays that isomeric complexes cis/trans-2a both reach a maximum yield of epoxide after $8 \mathrm{~h}$ reaction time (65 and 69\%), after which no conversion of cyclooctene occurs. Also, the yield of epoxide remains constant, indicating that complexes cis/trans-2a to do not further react with the formed epoxide. Based on the displayed similar activity (within experimental error), it seems that epoxidation catalysis is rather insensitive to stereoisomers. The same observation was made for the two $N, N$-cis/trans stereoisomers of $\left[\operatorname{ReOCl}(\mathrm{Oz})_{2}\right]\left(\mathrm{TON}\right.$ trans-[ReOCl$\left.(\mathrm{Oz})_{2}\right]=30 ; \mathrm{TON}$ cis-[ReOCl $\left.\left.(\mathrm{oz})_{2}\right]=40\right) .^{21}$ The positive influence of the electron-withdrawing nitro group in cis-2b is easily visible from the data displayed in Fig. 5. Complex cis-2b reaches $>95 \%$ conversion to epoxide after only $12 \mathrm{~h}$. In any given time interval it shows a higher activity than unsubstituted complex cis-2a. For the chlorido/alkoxido complexes $\left[\operatorname{ReOX}(\mathbf{L 1 a})_{2}\right](\mathbf{3 a} / \mathbf{4 a})$ and $[\operatorname{ReOX}$ $\left.(\mathbf{L 1 b})_{2}\right](\mathbf{3 b} / \mathbf{4 b})$ the data presented in Fig. 6 shows that both complexes equipped with the $\mathrm{NO}_{2}$-substituted ligand $\mathbf{L 1 b}$ have a higher catalytic activity than with un-substituted ligand L1a. Ethoxido-complex $\mathbf{4 b}$ proved to be the most active catalyst of the four (TON = 84), also showing the highest initial rate, reaching a $\mathrm{TOF}_{1 \mathrm{~h}}$ of $59 \mathrm{~h}^{-1}$ in the first hour (Table 2). In comparison, the respective chlorido-complex $\mathbf{3 b}$ shows a smaller $\mathrm{TOF}_{1} \mathrm{~h}$ of $22 \mathrm{~h}^{-1}$ in the first hour, but a similar activity after $8 \mathrm{~h}(\mathrm{TON}=82)($ Table 2$) \cdot{ }^{21}$ Both complexes $3 \mathbf{b}$ and $4 \mathbf{b}$ reach a maximum yield of epoxide after $8 \mathrm{~h}$. After that time, the amount of epoxide remains constant in case of $\mathbf{3 b}$.

In contrast to chlorido-complex $\mathbf{3} \mathbf{b}$, the formed epoxide gets consumed again by ethoxido-complex $\mathbf{4 b}$ at longer reaction times, dropping from $84 \%$ after 8 h to $66 \%$ after $24 \mathrm{~h}$. This behavior is often caused by over-oxidation of the epoxide to cyclooctanone or hydrolytic ring-opening to the respective diol. Complexes 3a and $\mathbf{4 a}$, equipped with the unsubstituted ligand L1a, produced a similar yield of epoxide after $24 \mathrm{~h}$, albeit with a quite different activity profile. Similar to ethoxido complex $\mathbf{4 b}$, the symmetric methoxido-complex $4 \mathbf{a}$ showed a higher initial reaction rate $\left(\mathrm{TOF}_{1 \mathrm{~h}}=11 \mathrm{~h}^{-1}\right)$ compared to asymmetric chlorido-complex 3a $\left(\mathrm{TOF}_{1 \mathrm{~h}}=6.4 \mathrm{~h}^{-1}\right)$. Complex 4a reached a maximum productivity after $8 \mathrm{~h}$, after which the yield of epoxide remained unchanged, similar to $\mathbf{4 b}$. Complex $\mathbf{3 a}$ showed a slow but steady increase in epoxide over the $24 \mathrm{~h}$ reaction time without reaching a plateau (Fig. 6).

An overview of calculated turnover numbers (TONs) and turnover frequencies (TOFs) is given in Table 2. With the data at hand, a trend can be observed that both symmetric OMe/ OEt-ligated complexes $\mathbf{4 a}$ and $\mathbf{4} \mathbf{b}$ are more active in epoxidation catalysis compared to their asymmetric Cl-ligated analogues $\mathbf{3 a}$ and $\mathbf{3 b}$. In literature, there are only few other published examples of such $\mathrm{Cl} / \mathrm{OR}$ substituted pairs of complexes, that were tested in cyclooctene epoxidation. ${ }^{12,13}$ Two examples are complexes $\left[\mathrm{ReOX}(\mathrm{icq})_{2}\right]^{12}(\mathrm{X}=\mathrm{Cl}$ or $\mathrm{OMe}$, icq $=$ isoquinoline-1-carboxylic acid $)$ and $\left[\mathrm{ReOX}(\mathrm{pic})_{2}\right]^{13}(\mathrm{X}=\mathrm{Cl}$ or OMe, pic $=$ picolinic acid). These complexes differ in their chemistry from $\left[\mathrm{ReO}(\mathrm{X})(\mathbf{L 1})_{2}\right]$ complexes quite significantly. Both chlorido complexes adopt the asymmetric $N, N$-cis configuration in the solid state, which is also retained in both methoxido ligands. In cyclooctene epoxidation, the observed data does not allow to deduce a simple trend for chlorido substitution with an alkoxido ligand. Whereas for $\left[\mathrm{ReOX}(\mathrm{pic})_{2}\right]$ both complexes $(\mathrm{X}=$ $\mathrm{Cl}$ or $\mathrm{OMe}$ ) have essentially the same catalytic activities, ${ }^{13}[\mathrm{ReO}$ $\left.(\mathrm{OMe})(\mathrm{icq})_{2}\right]$ showed higher activities compared to $[\mathrm{ReOCl}$ (icq) $\left.)_{2}\right] \cdot{ }^{12}$ In case of both pairs of chlorido/alkoxido complexes $\mathbf{3 a} / \mathbf{4 a}$ and $\mathbf{3} \mathbf{b} / \mathbf{4} \mathbf{b}$, the substitution of the chlorido with an alkoxido ligand results in a more active catalyst, especially in the first $4 \mathrm{~h}$ of reaction time. If this higher activity is a result of the alkoxido ligand or the isomerization to a symmetric isomer cannot be answered with the data at hand. A substantial increase of catalyst activity is effected by the electron-withdrawing ligand L1b.

Table 2 TON and TOF $\left[\mathrm{h}^{-1}\right]$ for cyclooctene epoxidation of catalysts cis/trans-2a, cis-2b, 3a/4a and 3b/4b

\begin{tabular}{llllllll}
\hline & cis-2a & trans-2a & cis-2b & 3a & 4a & 3b \\
\hline${\text { TON }\left(\mathrm{TOF} \mathrm{h}^{-1}\right)}$ & $69(8.6)$ & $65(8.1)$ & $95(7.9)$ & $37(1.5)$ & $39(4.8)$ & $82(3.4)$ \\
TOF $^{a}\left[\mathrm{~h}^{-1}\right]$ & 8.6 & 8.1 & 7.9 & 1.5 & 4.8 & $84(9.9)$ \\
$\operatorname{TOF}^{b}{ }_{1 \mathrm{~h}}\left[\mathrm{~h}^{-1}\right]$ & 47 & 32 & 72 & 6.4 & 11 & 22
\end{tabular}

General conditions: $1 \mathrm{~mol} \%$ catalyst loading, 3 equiv. TBHP (5.5 $\mathrm{M}$ in decane), $\mathrm{CHCl}_{3}, 50{ }^{\circ} \mathrm{C}$; data for $3 \mathbf{a}$ and $3 \mathbf{b}$ from ref. $21 .{ }^{a}$ TOF calculated after maximum conversion. ${ }^{b}$ TOF calculated after $1 \mathrm{~h}$. 
Mechanistic investigations in rhenium epoxidation chemistry are dominated by the chemistry of MTO, where both a peroxido and a bis-peroxido complex could be identified as catalytically active intermediates. ${ }^{5,15,29}$ Considering the electrophilic nature of the oxygen atom transfer from such a peroxide moiety to the olefin, a beneficial effect of electron-withdrawing ligands is expected, as such ligands withdraw electron density form the rhenium center and thereby increase the electrophilicity of a coordinated peroxide ligand. Exactly this behaviour, higher activity in epoxidation catalysis, was observed for ligand HL1b over HL1a. It also explains the lesser influence of stereoisomerism, as observed for cis/trans-2a. The mechanism of epoxidation for oxidorhenium(v) complexes is much less investigated, and an analogous peroxide complex could so far not be observed. There is however some evidence that a sequential oxidation of the starting mono-oxido to a bis-oxido and finally also a tris-oxido rhenium(VII) species is occurring on the way to the catalytic active species. Such a tris-oxido complex could then enter a catalytic cycle very similar to MTO. ${ }^{10,11,17,30}$

\section{Conclusions}

Within this manuscript we present a further example of stereoisomeric cis/trans-complexes in oxidorhenium(v) chemistry. Complexes cis-2a and trans-2a could be isolated, and their stereochemistry characterized by single crystal X-ray diffraction analysis. They are the first example of a pair of such stereoisomers that were tested in epoxidation catalysis. The influence of electron-withdrawing substituents was probed by complex cis-2b. Furthermore, another example of a reaction of an oxidorhenium(v) complex with an alcoholic solvent is presented, namely the formation of ethoxido complex $\mathbf{4 b}$ in $\mathrm{EtOH}$ in presence of the base lutidine. A similar reaction had been observed for methoxido complex $4 \mathrm{a}$, obtained in $\mathrm{MeOH}$ in the presence of $\mathrm{NaH}$. The complexes cis/trans-2a, cis-2 $\mathbf{b}, \mathbf{4 a}$ and $\mathbf{4 b}$ where then tested in catalytic epoxidation of cyclooctene and compared to their respective counterparts $\mathbf{3 a}$ and $\mathbf{3} \mathbf{b}$. The activities between complexes did vary significantly, with yields of epoxide found between 37 and 95\%. The two stereoisomers cis and trans-2a have a very similar catalytic activity profile, not influenced by the position of the ligands around the rhenium center. For the chlorido/alkoxido-complexes $\mathbf{3 a} / \mathbf{3} \mathbf{b}$ and $\mathbf{4 a} / \mathbf{4} \mathbf{b}, \mathbf{a}$ twice as high catalytic activity of complexes with the nitro-substituted ligand L1b (3b and $\mathbf{4 b}$ ) was observed compared to complexes containing the unsubstituted ligand L1a (3a and 4a). The highest activity was displayed by complex cis-2b, again showing the positive effect of nitro-substituted ligand L1b. We had previously observed a similar beneficial effect of electronwithdrawing substituents on pyrazole-phenol ligands in epoxidation activity. ${ }^{24,25}$ Selectivities towards epoxide were high for all tested complexes. Only in case of ethoxido-complex $\mathbf{4 b}$, epoxide was further consumed to other products at longer reaction times. The main side product observed was ringopened cyclooctane diol. To summarize, the electron-withdrawing nature of ligand HL1b is a more important contri- bution to catalyst activity than stereoisomerism (cis/trans) or nature of monodentate ligand $\mathrm{X}(\mathrm{Cl} v s$. OMe/OEt).

\section{Materials and methods}

\section{General}

The rhenium precursors $\left[\mathrm{ReOCl}_{3}\left(\mathrm{PPh}_{3}\right)_{2}\right]^{31}$ and $\left[\mathrm{ReOCl}_{3}\left(\mathrm{OPPh}_{3}\right)\left(\mathrm{SMe}_{2}\right)\right]^{32}$ were prepared according to previously published methods. The ligands $\mathrm{HL1a}^{33}$ and $\mathrm{HL1b}^{34}$ were synthesized by published routes. Syntheses of complexes cis-2a, $\mathbf{4} \mathbf{a},{ }^{19} \mathbf{3} \mathbf{a}$ and $\mathbf{3} \mathbf{b}^{21}$ were previously published. Additional unpublished analytical data (IR and UV-Vis data of 4a) has been included here. Chemicals were purchased from commercial sources and were used without further purification. NMR spectra were recorded with a Bruker $(300 \mathrm{MHz})$ instrument. Chemical shifts are given in $\mathrm{ppm}$ and are referenced to residual protons in the solvent. Signals are described as $\mathrm{s}$ (singlet), bs (broad singlet), d (doublet), dd (doublet of doublet), $\mathrm{t}$ (triplet), qd (quartet of doublets), m (multiplet) and coupling constants $(J)$ are given in Hertz $(\mathrm{Hz})$. Mass spectra were recorded with an Agilent 5973 MSD - Direct Probe using the EI ionization technique. Samples for infrared spectroscopy were measured on a Bruker Optics ALPHA FT-IR Spectrometer equipped with an ATR diamond probe head. GC-MS measurements were performed on an Agilent 7890 A with an Agilent 19091J-433 column coupled to a mass spectrometer type Agilent 5975 C. Elemental analyses were carried out using a Heraeus Vario Elementar automatic analyzer at the Graz University of Technology. Crystallographic data (excluding structure factors) for cis-2a, trans-2a and cis-2b were deposited with the Cambridge Crystallographic Data Center as supplementary publication no. CCDC 1854788, 1854789 and 2011198.†

\section{Epoxidation of olefin}

In a typical experiment, $2-3 \mathrm{mg}$ of catalyst ( $1 \mathrm{~mol} \%$ ) were dissolved in $0.5 \mathrm{~mL} \mathrm{CHCl}_{3}$ and mixed with cyclooctene (1 equiv.), $50 \mu \mathrm{L}$ of mesitylene (internal standard) and were heated to the reaction temperature. A Heidolph Parallel Synthesizer 1 was used for all epoxidation experiments. Then the oxidant (3. equiv.) was added. Aliquots for GC-MS $(20 \mu \mathrm{L})$ were withdrawn at given time intervals, quenched with $\mathrm{MnO}_{2}$ and diluted with HPLC grade EtOAc. The reaction products were analysed by GC-MS (Agilent 7890 A with an Agilent 19091J-433 column coupled to a mass spectrometer type Agilent 5975 C), and the epoxide produced from each reaction mixture was quantified vs. mesitylene as the internal standard.

Synthesis of complex $\left[\operatorname{ReOCl}_{2}\left(\mathbf{P P h}_{3}\right)(\mathrm{L1a})\right]$ trans-2a. The trans-dichlorido complex trans-2a is formed in an isomeric mixture with cis-2a under the synthesis conditions previously described.$^{19}$ Ligand HL1a (492 mg, $2.0 \mathrm{mmol}, 1$ equiv.) and $\left[\operatorname{ReOCl}_{3}\left(\mathrm{PPh}_{3}\right)_{2}\right](1.66 \mathrm{~g}, 2.0 \mathrm{mmol}, 1$ equiv. $)$ were mixed in $\mathrm{CH}_{3} \mathrm{CN}(40 \mathrm{ml})$ and stirred under refluxing conditions for $4 \mathrm{~h}$. The solution turned dark green while heated to refluxing temperatures. Upon cooling to rt, cis-2a precipitated first as a 
green, micro-crystalline solid. ${ }^{19}$ The acetonitrile supernatant was concentrated to $\mathrm{ca}$. $10 \mathrm{~mL}$ of volume and stored at $8{ }^{\circ} \mathrm{C}$, upon which analytically pure trans-2a precipitated as deepgreen solid (160 mg, $220 \mu \mathrm{mol}, 11 \%$ ). Recrystallization by slow evaporation from a concentrated acetonitrile solution yields single crystals with one molecule of $\mathrm{CH}_{3} \mathrm{CN}$ in the unit cell. ${ }^{1} \mathrm{H}$ NMR (300 MHz, chloroform-d) $\delta$ 7.91-7.80 (m, 6H) and 7.56-7.42 (m, 9H, $\left.\mathrm{PPh}_{3}\right), 7.75$ (dd, $\left.J=8.0,1.8 \mathrm{~Hz}, 1 \mathrm{H}, \mathrm{Ar}\right)$, 7.12-7.03 (m, 1H, Ar), 6.96-6.88 (m, 1H, Ar), 5.71 (d, $J=8.4 \mathrm{~Hz}$, $1 \mathrm{H}, \mathrm{Ar}), 4.58\left(\mathrm{~s}, 2 \mathrm{H},-\mathrm{CH}_{2}-\right), 1.82\left(\mathrm{~s}, 6 \mathrm{H},-\mathrm{CH}_{3}\right) .{ }^{13} \mathrm{C}$ NMR (75 MHz, chloroform-d) $\delta 161.83,135.95\left(C_{\mathrm{ar}}-\mathrm{H}\right), 135.04$ $\left(\mathrm{PPh}_{3}\right), 134.91\left(\mathrm{PPh}_{3}\right), 131.38\left(\mathrm{PPh}_{3}\right), 131.18\left(C_{\mathrm{ar}}-\mathrm{H}\right), 130.93$, 130.20, 128.62, 128.48, $119.07\left(C_{\mathrm{ar}}-\mathrm{H}\right), 118.60\left(C_{\mathrm{ar}}-\mathrm{H}\right), 72.60$ $\left(-\mathrm{CH}_{2}-\right), 27.81\left(-\mathrm{CH}_{3}\right)$ (proton-carrying carbons assigned via HSQC, some C atoms are obscured); ${ }^{31} \mathrm{P}$ NMR $(121 \mathrm{MHz}$, chloroform-d) $\delta$-5.35. ATR-IR ( $\left.\mathrm{cm}^{-1}\right): 3058(\mathrm{w}), 2952(\mathrm{w}), 1610$ $(\mathrm{m}, \mathrm{C}=\mathrm{N}), 1590(\mathrm{~m}, \mathrm{C}=\mathrm{N}), 1448(\mathrm{~m}), 1434(\mathrm{~m}), 1266(\mathrm{~m}), 1087$ (m), 968 (s, Re=O), $885(\mathrm{~m}), 750$ (s), 685 (s), 530 (s), 510 (s), $489(\mathrm{~m}), 391(\mathrm{w})$; EI-MS (m/z): $725.1\left(\mathrm{M}^{+}\right) ; \mathrm{UV}\left(\mathrm{CH}_{2} \mathrm{Cl}_{2}\right) \lambda_{\max }$, $\mathrm{nm}(\varepsilon)$ : 635 (69); elemental analysis calculated for $\mathrm{C}_{29} \mathrm{H}_{27} \mathrm{Cl}_{2} \mathrm{NO}_{3} \mathrm{PRe} \cdot \mathrm{CH}_{3} \mathrm{CN}$ (725.6 $\mathrm{g} \mathrm{mol}^{-1}$ ): $\mathrm{C} 48.56, \mathrm{H} \mathrm{3.94,} \mathrm{N}$ 3.65; found C 49.38, H 3.81, N 3.80 .

Synthesis of complex $\left[\operatorname{ReOCl}_{2}\left(\mathrm{PPh}_{3}\right)(\mathrm{L1b})\right]$ cis-2b. Ligand HL1b (131 mg, 0.55 mmol, 1 equiv.) and $\left[\operatorname{ReOCl}_{3}\left(\mathrm{PPh}_{3}\right)_{2}\right]$ (0.462 mg, 0.55 mmol, 1 equiv.) were mixed in $\mathrm{CH}_{3} \mathrm{CN}(30 \mathrm{ml})$ and stirred under refluxing conditions for $4 \mathrm{~h}$. The solution turned dark green while heated to refluxing temperatures. After cooling to $\mathrm{rt}$ the acetonitrile was removed to give an oily solid. Most of the side product $\mathrm{PPh}_{3}$ was removed from crude cis-2b by repeated washing with $\mathrm{Et}_{2} \mathrm{O}$, where cis-2b is poorly soluble. Crude cis-2b was then extracted with EtOAc giving a deep-green solution. Analytical pure cis-2b was obtained as a dark green crystalline solid by re-crystallization from a saturated EtOAc solution (90 mg, $116 \mu \mathrm{mol}, 21 \%$ ). ${ }^{1} \mathrm{H}$ NMR (300 MHz, chloroform-d) $\delta 8.54$ (d, $J=2.9 \mathrm{~Hz}, 1 \mathrm{H}, \mathrm{Ar}), 7.81$ (dd, $J=9.2,2.9 \mathrm{~Hz}, 1 \mathrm{H}, \mathrm{Ar}), 7.53-7.37\left(\mathrm{~m}, 9 \mathrm{H}, \mathrm{PPh}_{3}\right), 6.26(\mathrm{~d}$, $J=9.2 \mathrm{~Hz}, 1 \mathrm{H}, \mathrm{Ar}), 4.52\left(\mathrm{~d}, J=8.3 \mathrm{~Hz}, 1 \mathrm{H},-\mathrm{CH}_{2}-\right), 4.18(\mathrm{~d}, J=$ $\left.8.3 \mathrm{~Hz}, 1 \mathrm{H},-\mathrm{CH}_{2}-\right), 1.78\left(\mathrm{~s}, 3 \mathrm{H},-\mathrm{CH}_{3}\right), 0.60\left(\mathrm{~s}, 3 \mathrm{H},-\mathrm{CH}_{3}\right) \cdot{ }^{13} \mathrm{C}$ NMR (75 MHz, chloroform-d) $\delta$ 138.56, 134.51, 134.38, 131.97 $\left(\mathrm{PPh}_{3}\right), 131.94\left(\mathrm{PPh}_{3}\right), 131.32\left(C_{\mathrm{ar}}-\mathrm{H}\right), 130.10,129.42,129.05$ $\left(\mathrm{PPh}_{3}\right), 128.91\left(\mathrm{PPh}_{3}\right), 127.46\left(C_{\mathrm{ar}}-\mathrm{H}\right), 120.39\left(C_{\mathrm{ar}}-\mathrm{H}\right), 79.21$ $\left(-\mathrm{CH}_{2}-\right), 75.49\left(-\mathrm{CH}_{2}-\right), 29.06\left(-\mathrm{CH}_{3}\right), 24.37\left(-\mathrm{CH}_{3}\right)$ (protoncarrying carbons assigned via HSQC, some $\mathrm{C}$ atoms are obscured); ${ }^{31} \mathrm{P}$ NMR (121 MHz, chloroform-d) $\delta-17.36$. ATR-IR $\left(\mathrm{cm}^{-1}\right)$ : $3059(\mathrm{w}), 2893(\mathrm{w}), 1609(\mathrm{~m}, \mathrm{C}=\mathrm{N}), 1314\left(\mathrm{~s},-\mathrm{NO}_{2}\right)$, $1285\left(\mathrm{~m},-\mathrm{NO}_{2}\right), 988$ (s, Re=O), $847(\mathrm{~m}), 744(\mathrm{~s}), 710$ (s), 525 (s), $507(\mathrm{~s}), 491(\mathrm{~m})$; EI-MS (m/z): $262.1\left(\mathrm{PPh}_{3}\right)$ (no $\mathrm{M}^{+}$visible); $\mathrm{UV}\left(\mathrm{CH}_{2} \mathrm{Cl}_{2}\right) \lambda_{\text {max }}, \mathrm{nm}(\varepsilon): 649$ (82); elemental analysis calculated for $\mathrm{C}_{29} \mathrm{H}_{26} \mathrm{Cl}_{2} \mathrm{~N}_{2} \mathrm{O}_{5} \mathrm{PRe}\left(770.6 \mathrm{~g} \mathrm{~mol}^{-1}\right)$ : $\mathrm{C} 45.20, \mathrm{H} 3.40, \mathrm{~N}$ 3.64; found C 45.81, H 3.51, N 3.64.

Additional analytical data for $\left[\operatorname{ReO}(\mathrm{OMe})(\mathrm{L1a})_{2}\right] \quad 4 a$. Synthesis of $\mathbf{4 a}$ has been previously described. ${ }^{19}$ ATR-IR $\left(\mathrm{cm}^{-1}\right)$ : $2965(\mathrm{w}), 2899(\mathrm{w}), 2809(\mathrm{w}), 1607$ and $1568(\mathrm{~s}, \mathrm{C}=\mathrm{N})$, 1467 (m), 1245 (m), 1108 (m), 1076 (m), 927 (s, Re=O), 851 $(\mathrm{m}), 760(\mathrm{~s}), 697(\mathrm{~m}), 664(\mathrm{~m}), 577(\mathrm{~m}), 482(\mathrm{~s}) ; \mathrm{UV}\left(\mathrm{CH}_{2} \mathrm{Cl}_{2}\right)$ $\lambda_{\text {max }}, \operatorname{nm}(\varepsilon): 580(116)$.
Synthesis of complex $\left[\operatorname{ReO}(\mathrm{OEt})(\mathrm{L1b})_{2}\right] 4 \mathrm{~b}$. Ligand HL1b (0.382 g, 1.62 mmol, 2.1 equiv.), $\left[\mathrm{ReOCl}_{3}\left(\mathrm{OPPh}_{3}\right)\left(\mathrm{SMe}_{2}\right)\right]$ ( $0.500 \mathrm{~g}, 0.770 \mathrm{mmol}, 1$ equiv.) and 2,6-dimethylpyridine (lut, $0.251 \mathrm{~g}, 2.34 \mathrm{mmol}, 3$ equiv.) were mixed in $\mathrm{EtOH}(20 \mathrm{ml})$ and stirred under refluxing conditions for $2 \mathrm{~h}$. The solution turned dark brown. Upon cooling to $\mathrm{rt}$, crude $\mathbf{4 b}$ precipitated as a brownish micro-crystalline solid. The solid was isolated and washed twice with $\mathrm{Et}_{2} \mathrm{O}$ to remove residual lut. $\mathrm{HCl}$. After drying, $0.50 \mathrm{~g}$ of analytically pure $\mathbf{4 b}$ were obtained as a brown micro-crystalline solid (0.70 mmol, 91\%). ${ }^{1} \mathrm{H}$ NMR (300 MHz, chloroform-d) $\delta 8.88$ (d, $J=2.9 \mathrm{~Hz}, 2 \mathrm{H}, \mathrm{Ar}$ ), 8.23 (dd, $J=9.3$, $2.9 \mathrm{~Hz}, 2 \mathrm{H}, \mathrm{Ar}$ ), 7.02 (d, $J=9.3 \mathrm{~Hz}, 2 \mathrm{H}, \mathrm{Ar}), 4.55$ (d, $J=8.4 \mathrm{~Hz}$, $\left.2 \mathrm{H},-\mathrm{CH}_{2}-\right), 4.45\left(\mathrm{~d}, J=8.4 \mathrm{~Hz}, 2 \mathrm{H},-\mathrm{CH}_{2}-\right), 3.50(\mathrm{qd}, J=7.0$, $\left.3.9 \mathrm{~Hz}, 2 \mathrm{H},-\mathrm{OCH}_{2} \mathrm{CH}_{3}\right), 1.84\left(\mathrm{~s}, 6 \mathrm{H},-\mathrm{CH}_{3}\right), 1.80\left(\mathrm{~s}, 6 \mathrm{H},-\mathrm{CH}_{3}\right)$, $0.81\left(\mathrm{t}, J=7.0 \mathrm{~Hz}, 3 \mathrm{H},-\mathrm{OCH}_{2} \mathrm{CH}_{3}\right) ;{ }^{13} \mathrm{C}$ NMR $(75 \mathrm{MHz}$, chloroform-d) $\delta 179.00,166.78,138.42,129.97,128.81,122.49$ (all $\mathrm{Ar}), 110.08(C=\mathrm{N}), 81.54\left(-\mathrm{CH}_{2}-\right), 74.61\left(-C\left(\mathrm{CH}_{3}\right)_{2}{ }^{-}\right), 66.07$ $\left(-\mathrm{OCH}_{2} \mathrm{CH}_{3}\right), 27.16\left(-\mathrm{CH}_{3}\right), 27.10\left(-\mathrm{CH}_{3}\right), 17.84\left(-\mathrm{OCH}_{2} \mathrm{CH}_{3}\right)$. ATR-IR (cm $\left.{ }^{-1}\right)$ : $2969(\mathrm{w}), 2854(\mathrm{w}), 1608(\mathrm{~s}, \mathrm{C}=\mathrm{N}), 1556(\mathrm{w})$, $1468\left(\mathrm{~m},-\mathrm{NO}_{2}\right), 1409(\mathrm{w}), 1305\left(\mathrm{~s},-\mathrm{NO}_{2}\right), 1275(\mathrm{~m}), 1112(\mathrm{~m})$, $1067(\mathrm{~m}), 947(\mathrm{~m}), 912(\mathrm{~m}, \mathrm{Re}=\mathrm{O}), 833(\mathrm{~m}), 748(\mathrm{w}), 704(\mathrm{~m})$, $666(\mathrm{~m}), 532(\mathrm{~m}), 408(\mathrm{~m})$; EI-MS (m/z): $718.3\left(\mathrm{M}^{+}\right), 673.3\left(\mathrm{M}^{+}-\right.$ OEt); UV $\left(\mathrm{CH}_{2} \mathrm{Cl}_{2}\right) \lambda_{\max }, \mathrm{nm}(\varepsilon): 544$ (238); elemental analysis calculated for $\mathrm{C}_{24} \mathrm{H}_{27} \mathrm{~N}_{4} \mathrm{O}_{10} \mathrm{Re}\left(717.7 \mathrm{~g} \mathrm{~mol}^{-1}\right)$ : C 40.16, H 3.79, N 7.81; found C 40.13, H 3.79, N 7.57.

\section{Conflicts of interest}

There are no conflicts to declare.

\section{Acknowledgements}

Financial support from NAWI Graz is gratefully acknowledged.

\section{Notes and references}

1 W. A. Herrmann, J. G. Kuchler, J. K. Felixberger, E. Herdtweck and W. Wagner, Angew. Chem., Int. Ed., 1988, 27, 394-396.

2 (a) W. A. Herrmann, R. W. Fischer and D. W. Marz, Angew. Chem., Int. Ed., 1991, 30, 1638-1641; (b) W. A. Herrmann and M. Wang, Angew. Chem., Int. Ed., 1991, 30, 1641-1643.

3 (a) C. C. Romão, F. E. Kühn and W. A. Herrmann, Chem. Rev., 1997, 97, 3197-3246; (b) A. J. L. Pombeiro, M. F. C. G. da Silva and R. H. Crabtree, in Encyclopedia of Inorganic and Bioinorganic Chemistry, John Wiley \& Sons, Inc, 2011; (c) R. G. Harms, W. A. Herrmann and F. E. Kühn, Coord. Chem. Rev., 2015, 296, 1-23.

4 J. W. Kück, R. M. Reich and F. E. Kühn, Chem. Rec., 2016, 16, 349-364.

5 S. Huber, M. Cokoja and F. E. Kühn, J. Organomet. Chem., 2014, 751, 25-32.

6 S. Yamazaki, Org. Biomol. Chem., 2007, 5, 2109-2113. 
7 (a) W. Adam and C. M. Mitchell, Angew. Chem., Int. Ed., 1996, 35, 533-535; (b) T. R. Boehlow and C. D. Spilling, Tetrahedron Lett., 1996, 37, 2717-2720; (c) P. Altmann, M. Cokoja and F. E. Kühn, Eur. J. Inorg. Chem., 2012, 32353239.

8 B. Machura, M. Wolff and I. Gryca, Coord. Chem. Rev., 2014, 275, 154-164.

9 W. A. Herrmann, J. Organomet. Chem., 1990, 382, 1-18.

10 W. A. Herrmann, M. U. Rauch and G. R. J. Artus, Inorg. Chem., 1996, 35, 1988-1991.

11 F. E. Kühn, M. U. Rauch, G. M. Lobmaier, G. R. J. Artus and W. A. Herrmann, Chem. Ber., 1997, 130, 1427-1431.

12 B. Machura, M. Wolff, E. Benoist, J. A. Schachner and N. C. Mösch-Zanetti, Dalton Trans., 2013, 42, 8827-8837.

13 B. Machura, M. Wolff, D. Tabak, J. A. Schachner and N. C. Mösch-Zanetti, Eur. J. Inorg. Chem., 2012, 3764-3773.

14 S. Dinda, M. G. B. Drew and R. Bhattacharyya, Catal. Commun., 2009, 10, 720-724.

15 F. E. Kühn, A. M. Santos and W. A. Herrmann, Dalton Trans., 2005, 34, 2483-2491.

16 (a) V. S. Sergienko and A. V. Churakov, Russ. J. Inorg. Chem., 2016, 61, 1708-1726; (b) V. S. Sergienko and A. V. Churakov, Russ. J. Inorg. Chem., 2017, 62, 1327-1342; (c) V. S. Sergienko, Russ. J. Inorg. Chem., 2017, 62, 751-759; (d) V. S. Sergienko and A. V. Churakov, Russ. J. Inorg. Chem., 2018, 63, 631-641; (e) B. Machura, Coord. Chem. Rev., 2005, 249, 591-612; (f) B. Machura, Coord. Chem. Rev., 2005, 249, 2277-2307.

17 M. Wolff and B. Machura, Rev. Inorg. Chem., 2020, 40, 4773.

18 B. Machura, M. Wolff, E. Benoist, J. A. Schachner, N. C. Mösch-Zanetti, K. Takao and Y. Ikeda, Polyhedron, 2014, 69, 205-218.

19 J. A. Schachner, B. Terfassa, L. M. Peschel, N. Zwettler, F. Belaj, P. Cias, G. Gescheidt and N. C. Mösch-Zanetti, Inorg. Chem., 2014, 53, 12918-12928.

20 J. Liu, D. Wu, X. Su, M. Han, S. Y. Kimura, D. L. Gray, J. R. Shapley, M. M. Abu-Omar, C. J. Werth and T. J. Strathmann, Inorg. Chem., 2016, 55, 2597-2611.

21 J. A. Schachner, B. Berner, F. Belaj and N. C. MöschZanetti, Dalton Trans., 2019, 48, 8106-8115.
22 (a) J. Liu, X. Su, M. Han, D. Wu, D. L. Gray, J. R. Shapley, C. J. Werth and T. J. Strathmann, Inorg. Chem., 2017, 56, 1757-1769; (b) B. Terfassa, J. A. Schachner, P. Traar, F. Belaj and N. C. Mösch-Zanetti, Polyhedron, 2014, 75, 141-145.

23 (a) B. Terfassa, P. Traar, M. Volpe, N. C. Mösch-Zanetti, V. J. T. Raju, N. Megersa and N. Retta, Eur. J. Inorg. Chem., 2011, 4434-4440; (b) N. Zwettler, J. A. Schachner, F. Belaj and N. C. Mösch-Zanetti, Inorg. Chem., 2016, 55, 59735982.

24 N. Zwettler, J. A. Schachner, F. Belaj and N. C. MöschZanetti, Inorg. Chem., 2014, 53, 12832-12840.

25 P. Traar, J. A. Schachner, L. Steiner, A. Sachse, M. Volpe and N. C. Mösch-Zanetti, Inorg. Chem., 2011, 50, 19831990.

26 B. Machura, M. Wolff, I. Gryca and R. Kruszynski, Polyhedron, 2012, 40, 93-104.

27 (a) B. Machura, R. Kruszynski and J. Kusz, Polyhedron, 2007, 26, 3455-3464; (b) B. Machura and J. Kusz, Polyhedron, 2008, 27, 923-932; (c) B. Machura, M. Wolff, W. Cieślik and R. Musioł, Polyhedron, 2013, 51, 263-274.

28 (a) B. Machura, R. Kruszynski and J. Kusz, Polyhedron, 2008, 27, 1679-1689; (b) W. K. Rybak, A. Skarżyńska, L. Szterenberg, Z. Ciunik and T. Głowiak, Eur. J. Inorg. Chem., 2005, 4964-4975; (c) B. Machura, M. Wolff, J. Kusz and R. Kruszynski, Polyhedron, 2009, 28, 2949-2964.

29 (a) I. V. Yudanov, J. Struct. Chem., 2007, 48, S111-S124; (b) F. E. Kühn, A. Scherbaum and W. A. Herrmann, J. Organomet. Chem., 2004, 689, 4149-4164; (c) J. H. Espenson, Chem. Commun., 1999, 479-488.

30 (a) R. Sarkar, A. Hens and K. K. Rajak, RSC Adv., 2015, 5, 15084-15095; (b) K. R. Grünwald, G. Saischek, M. Volpe and N. C. Mösch-Zanetti, Inorg. Chem., 2011, 50, 71627171.

31 J. Chatt and G. A. Rowe, J. Chem. Soc., 1962, 4019.

32 B. D. Sherry, R. N. Loy and F. D. Toste, J. Am. Chem. Soc., 2004, 126, 4510-4511.

33 P. G. Cozzi, C. Floriani, A. Chiesi-Villa and C. Rizzoli, Inorg. Chem., 1995, 34, 2921-2930.

34 H. C. Aspinall, O. Beckingham, M. D. Farrar, N. Greeves and C. D. Thomas, Tetrahedron Lett., 2011, 52, 5120-5123. 